\title{
Influence of melt processing conditions on poly(lactic acid) degradation: Molar mass distribution and crystallization
}

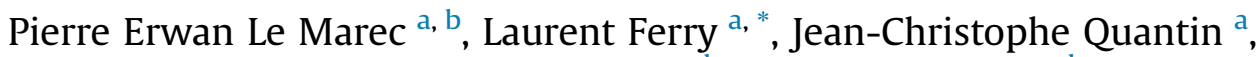 \\ Jean-Charles Bénézet ${ }^{\mathrm{a}}$, Frédéric Bonfils ${ }^{\mathrm{b}}$, Stéphane Guilbert ${ }^{\mathrm{b}}$, Anne Bergeret ${ }^{\mathrm{a}}$ \\ a Ecole des Mines d'Alès, Centre des Matériaux des Mines d'Alès (C2MA), 6 Avenue de Clavières, 30319 Alès Cedex, France \\ b UMR 1208 Ingénierie des Agropolymères et Technologies Emergentes (IATE), INRA/Agro.M/UM2/CIRAD, Campus de la Gaillarde, 2 Place Pierre Viala, \\ 34060 Montpellier Cedex 01, France
}

\begin{abstract}
A B S T R A C T
The degradation of poly(lactic acid) (PLA) during thermal-mechanical processing was studied and the influence of processing conditions on degradation rate was determined by size exclusion chromatography coupled with multi-angle light scattering (SEC-MALS). A two-parameter model accounting for both chain scission and recombination processes was used to describe the experimentally observed molar mass distribution. The degradation and recombination rate constants were determined for undried and dried PLA. It was highlighted that the effect of processing temperature (in the $170-210{ }^{\circ} \mathrm{C}$ range), processing time (until $30 \mathrm{~min}$ ) and shear rate (rotor speed varying from 0 to $150 \mathrm{rpm}$ ) on molar mass reduction can be relatively well simulated insofar as self-heating related to the mechanical energy conversion into heat was taken into account.

The influence of melt processing on the thermal behaviour of PLA was also investigated using temperature modulated differential scanning calorimetry (TMDSC). It was evidenced that the molar mass reduction affects the crystallizability of PLA. Cold crystallization temperature progressively decreases with decreasing molar mass and the metastable $\alpha^{\prime}$ phase is formed in place of the stable $\alpha$ phase. The $\alpha^{\prime}$ phase can be partially converted into $\alpha$ form during melting giving rise to a double-melting peak. The two peaks can be separated using reversing and non-reversing signals confirming that recrystallization of the $\alpha^{\prime}$ form occurs.
\end{abstract}

Keywords:

Poly(lactic acid) (PLA)

Melt processing

Thermal degradation

Molar mass

Crystallization

Simulation

\section{Introduction}

Nowadays, sustainability of raw materials is often considered as an added value and even, sometimes, as a requirement. As a result, bio-based and/or biodegradable polymer development receives much attention. Among all the so-called biopolymers, only a few of them (biopolyesters, e.g. poly(lactic acid) (PLA) or polyhydroxyalkanoates (PHA), polysaccharides and proteins) are already both bio-based and biodegradable. Unlike polysaccharides (starch, cellulose, chitin ...) and proteins (gluten, casein, keratin ...) which are directly extracted from biomass, PLA is a biopolyester produced by polymerization of lactic acid dimers obtained from starch fermentation [1]. Since it is somehow largely commercially available, PLA is often considered as a good alternative to petrobased polymers.

\footnotetext{
* Corresponding author. Tel.: +33 (0)4 66785358

E-mail address: laurent.ferry@mines-ales.fr (L. Ferry).
}

However, its thermal stability above the melting point remains very low and the ester linkages of PLA tend to degrade themselves during melt processing [2]. The final properties, e.g. mechanical properties, thermal behaviour and biodegradation rate, are then affected by the processing conditions [3-7].

Several mechanisms were postulated in order to describe the complex and various degradation reactions occurring in molten state: random chain scission [2,8], depolymerization [9], oxidative degradation [8], intermolecular $[9,10]$ and intramolecular transesterification [3,11-15], hydrolysis [16], pyrolytic elimination [16] and radical reactions [3]. Acidic end groups, residual catalyst and monomers or other impurities also increase the degradation rate [11].

It has been usually reported that PLA degradation during thermal treatment is mainly due to intramolecular transesterification reactions leading to cyclic oligomers of lactic acid and lactide $[9,14]$. Simultaneously, recombination occurs by ring opening insertion of cyclic oligomers into linear polyesters [14,15]. Intermolecular transesterification with short molecules could also result in a 
decrease of average molar mass [9]. Hydrolytic degradation depends on water content $[14,16]$. Pyrolytic elimination leads to molecules with acrylic end-groups [14], the colour formation being attributed to the apparition of conjugated double bonds [16].

Degradation during melt processing, i.e. under shear conditions, was studied in single [7] and twin-screw extruders [4,16], injection moulding machines $[6,7,17,18]$, and batch mixers [10]. In twinscrew extruders, Taubner and Shishoo [4] found that the molar mass reduction is dependent on residence time and temperature. They also found that moisture increases the degradation rate. However, in the harshest conditions, molar mass after extrusion was found to be the same in both case of dry and moist PLA, probably because degradation was so extensive that the presence of moisture in the polymer did not contribute to further degradation. Wang et al. [16] related the molar mass reduction to the colour formation using UV-visible spectroscopy and found that moisture does not influence the UV-visible spectra by forming conjugated double bonds while it reduces the molar mass. They concluded that pyrolytic elimination was the main degradation mechanism for dry PLA while an additional hydrolysis mechanism occurs in presence of moisture. Badia et al. [18] have shown that successive injection cycles induce a strong decrease of molar mass measured by viscometry. They highlighted that throughout reprocessing PLA cold crystallization appeared, indicating that chain scission emphasizes segmental dynamics.

Modelling degradation processes of polymers is generally achieved using a kinetic constant $k$ which takes an Arrhenius form to account for the thermally activated feature of phenomena. The evolution of molecular weight distribution can then be estimated using models based on population-balance equations considering that degradation results from chain scission and recombination [19]. The modelling of PLA degradation during thermal processing was poorly covered in the literature. Wachsen et al. [15] developed a statistical model to describe the degradation of PLA in the melt. Yu et al. [2] used the same kind of mathematical model to account for the thermal degradation of PLA under nitrogen by random chain scission. None of the works found in the literature considered the role of mechanical energy in degradation processes neither by the elevation of temperature due to viscous dissipation (degradation reactions favoured by thermal effects) nor by the shear stress (chain scission to due mechanical effects).

In this paper it was attempted to study first the influence of PLA drying, of mixing temperature in the $170-210{ }^{\circ} \mathrm{C}$ range and time up to $30 \mathrm{~min}$, on PLA degradation during processing considering a thermo-compression process. Then the influence of the rotor speed up to $150 \mathrm{rpm}$ on PLA degradation during processing in a batch mixer was investigated to separate mechanisms related to shear conditions from those related to temperature. In all cases the degradation rate was assessed by measuring the molar mass reduction. A statistical model was implemented to describe the experimental results. It was therefore possible to examine the respective role of each processing parameter which provides a powerful tool for further investigations on PLA based materials such as PLA/natural fibre biocomposites. In the last part of this paper, the consequences of PLA degradation on its crystallization ability were studied.

\section{Theoretical background: statistical model of polymer thermal degradation}

The influence of time on the molar mass evolution was modelled using a two-parameter model based on reactions schemes describing both degradation and recombination processes (equations (1) and (2)) [2,15]:
$P_{i} \rightarrow P_{i-j}+P_{j}$

$P_{i-j}+P_{j} \rightarrow P_{i}$

where $P_{i}$ is a PLA polymer chain with a degree $i$ of polymerization. Using two statistic rate constants $k_{\mathrm{d}}$ and $k_{\mathrm{c}}$ respectively for degradation reactions and recombination reactions, the evolution of the concentration of each species $P_{i}$ can be described by the following differential equation system (equation (3)):

$$
\begin{aligned}
\frac{\mathrm{d}\left[P_{i}\right]}{\mathrm{d} t}= & -k_{\mathrm{d}}(i-1)\left[P_{i}\right]+2 k_{\mathrm{d}} \sum_{j=i+1}^{\infty}\left[P_{j}\right]+\frac{1}{2} k_{\mathrm{c}} \sum_{j=1}^{i-1}\left[P_{j}\right]\left[P_{i-j}\right] \\
& -k_{\mathrm{c}}\left[P_{i}\right] \sum_{j=1}^{\infty}\left[P_{j}\right]
\end{aligned}
$$

The first term of equation ( 3 ) describes the $(i-1)$ possibilities of splitting of a molecule $P_{i}$. The second term describes every possible formation of this molecule by degradation of the molecules with a chain length $j$ greater than $i$. The third term represents every possible formation of this molecule by recombination of two molecules with chain lengths $j$ and $(i-j)$ lower than $i$. The last term describes every possible disappearance of this molecule due to its recombination with other species.

The influence of temperature on both constants was modelled with an Arrhenius law (equations (4)-(5)).

$k_{\mathrm{d}}=A_{\mathrm{d}} \exp \left[-\frac{E_{\mathrm{ad}}}{R T}\right]$

$k_{\mathrm{c}}=A_{\mathrm{c}} \exp \left[-\frac{E_{\mathrm{ac}}}{R T}\right]$

where $k_{\mathrm{d}}$ and $k_{\mathrm{c}}$ are respectively the degradation and recombination rate constants, $E_{\mathrm{ad}}$ and $E_{\mathrm{ac}}$ are the respective activation energies for the degradation and recombination processes, $A_{\mathrm{d}}$ and $A_{\mathrm{c}}$ are the pre-exponential factors, $R$ is the gas constant (8.314 $\mathrm{J} \mathrm{mol}^{-1} \mathrm{~K}^{-1}$ ), and $T$ is the polymer temperature (K).

A direct numerical integration of equation (3) for each individual molecular species is complicated and time consuming. Yu et al. [2] proposed to express the polymer chain length distribution using its moments $\lambda_{n}$ up to third-order:

$\lambda_{n}=\sum_{i=1}^{\infty} i^{n}\left[P_{i}\right] \quad(n=0,1,2,3)$

where $\lambda_{n}$ is the $n$th moment of distribution, $\lambda_{0}, \lambda_{1}, \lambda_{2}$ and $\lambda_{3}$ representing respectively the mean, variance, skewness and kurtosis of the distribution.

Using a z-transform to express the summations, the differential equation system becomes:

$\frac{\mathrm{d} \lambda_{0}}{\mathrm{~d} t}=k_{\mathrm{d}}\left(\lambda_{1}-\lambda_{0}\right)-\frac{k_{\mathrm{c}} \lambda_{0}^{2}}{2}$

$\frac{\mathrm{d} \lambda_{1}}{\mathrm{~d} t}=k_{\mathrm{d}}\left(\lambda_{1}-\lambda_{0}\right)$

$\frac{\mathrm{d} \lambda_{2}}{\mathrm{~d} t}=\frac{k_{\mathrm{d}}\left(\lambda_{1}-\lambda_{3}\right)}{3}-k_{\mathrm{c}} \lambda_{1}^{2}$

The following closure approximation (equation (10)) is made to solve the system: 
$\lambda_{3}=\frac{\lambda_{2}}{\lambda_{1} \lambda_{0}}\left[2 \lambda_{2} \lambda_{0}-\lambda_{1}^{2}\right]$

The number- and weight-molar masses as well as polydispersity index $Q$ are computed at each stage according to equations (11)-(13):

$\bar{M}_{\mathrm{n}}=m_{0} \frac{\lambda_{1}}{\lambda_{0}}$

$\bar{M}_{\mathrm{w}}=m_{0} \frac{\lambda_{2}}{\lambda_{1}}$

$Q=\frac{\bar{M}_{\mathrm{w}}}{\bar{M}_{\mathrm{n}}}=\frac{\lambda_{2} \lambda_{0}}{\lambda_{1}^{2}}$

where $m_{0}$ is the mass of the monomer unit (76.05 $\mathrm{g} \mathrm{mol}^{-1}$ for PLA).

\section{Materials and methods}

\subsection{PLA}

The homopolymer used in this paper was a commercial grade of PLA from NatureWorks ${ }^{\circledR}$ LLC (Ingeo ${ }^{\mathrm{TM}}$ 7000D). According to the supplier datasheets $[20,21]$, glass transition temperature $T_{\mathrm{g}}$ is about $52-58{ }^{\circ} \mathrm{C}$, melting temperature $T_{\mathrm{m}}$ is about $145-155^{\circ} \mathrm{C}$. These temperatures will be verified in a latter part. The D-isomer content was $6.4 \mathrm{wt} \%$. Density at room temperature is $1260 \mathrm{~kg} \mathrm{~m}^{-3}$ and the volume thermal expansion coefficient is $8.5 \times 10^{-3}{ }^{\circ} \mathrm{C}^{-1}$. For melt processing, temperatures between 170 and $230^{\circ} \mathrm{C}$ are recommended.

\subsection{Drying process}

To prevent PLA hydrolysis and possible lactide reformation, it is recommended to control moisture content before processing [20]. In order to observe the influence of moisture during melt mixing, PLA was used either undried or dried in an air dryer (Piovan) for $24 \mathrm{~h}$ at $60{ }^{\circ} \mathrm{C}$ with an air flow of $10 \mathrm{~m}^{3} \mathrm{~h}^{-1} \mathrm{~kg}^{-1}$ at a dew point of $-35{ }^{\circ} \mathrm{C}$. Moisture content was determined by the Karl Fischer's method and was found to be around 1500 ppm and below 200 ppm before and after drying respectively.

\subsection{Thermocompression moulding conditions}

In order to simulate a thermal degradation without mechanical effects, samples were prepared by thermo-compression moulding (Darragon $100 \mathrm{kT}, 400 \times 400 \mathrm{~mm}^{2}$ ) at $170^{\circ} \mathrm{C}, 190{ }^{\circ} \mathrm{C}$ and $210^{\circ} \mathrm{C}$ for $10 \mathrm{~min}, 20 \mathrm{~min}$ and $30 \mathrm{~min}$. 130 bar pressure was applied during the last $3 \mathrm{~min}$ of the cycle. The plate dimension was $150 \times 150 \mathrm{~mm}^{2}$ and its thickness was $4 \mathrm{~mm}$.

\subsection{Batch mixing conditions}

In order to introduce more intense viscous friction effects, PLA was mixed in a Haake Rheomix 3000 batch mixer using two counter-rotating rotors with a gear ratio of $2 / 3$. The mixing time $t_{\text {mix }}$ was fixed at 10 min to study the influence of rotor speed $\mathrm{N}(40$, $50,75,100$ and $150 \mathrm{rpm}$ ) and mixing set temperature $T_{\mathrm{c}}$ (170 and $190^{\circ} \mathrm{C}$ ). Mixing was performed in air. $250 \mathrm{~g}$ of PLA was introduced in the $300 \mathrm{~cm}^{3}$ mixing chamber. Depending on the process parameters, the filling ratio in steady-state was estimated, using the volume thermal expansion coefficient, between 76 and 78\% (optimum filling ratio is about 70\% according to the literature [22-24]). The influence of mixing time (10,20 and $30 \mathrm{~min}$ ) was studied at 40,
75 and $150 \mathrm{rpm}$ and at 170 and $190{ }^{\circ} \mathrm{C}$. Three trials were performed for each couple of parameters $\left[T_{\mathrm{c}}, N\right]$. The aim of this part was not to determine an optimized set of processing parameters but to investigate their respective influence on PLA degradation.

The torque $T(t)$ and the average polymer temperature $T_{\mathrm{p}}(t)$ were recorded during each trial using respectively a torque sensor on the rotor shaft and a thermocouple in the mixing chamber. Torque measurements were used to calculate the specific mechanical energy (SME) according to equation (14) [25]. Pressure evolution was not recorded.

$\operatorname{SME}(t)=\frac{\omega}{m} \int_{0}^{t} \Gamma(t) \mathrm{d} t$

where $t$ is the mixing time, $\omega$ is the rotor speed $\left(\operatorname{rad~s}^{-1}\right)$ and $m$ is the mass of polymer.

After mixing PLA was collected by scraping walls and rotors of the internal mixer for further characterization. Polymer was cooled down naturally to ambient temperature. Since sample weight and room temperature were kept constant, it was expected that all samples underwent similar thermal history. Slight differences may result from variation in sample geometry (due to the collecting mode) or from the initial temperature.

\subsection{Size-exclusion chromatography with multi-angle light scattering}

The average molar masses and polydispersity index were determined using size-exclusion chromatography coupled with multi-angle light scattering detector (SEC-MALS).

The samples $(90 \pm 1 \mathrm{mg}$ ) were dissolved in $30 \mathrm{~mL}$ of HPLC-grade tetrahydrofuran (THF) stabilized with 2,6-di-tert-butyl-4-methylphenol (BHT). After storing for 2 days in the dark at $30^{\circ} \mathrm{C}$, the solutions were filtered with disposable filters (PTFE membrane, $0.45 \mu \mathrm{m}$ ) and injected in SEC-MALS. The SEC equipment consisted of an online degasser (Elite ${ }^{\mathrm{TM}}$, Alltech), a Shimadzu LC-20AD pump, a refractive index detector (Waters 2410) and a multi-angle light scattering detector (Dawn DSP, Wyatt Technology). The columns were three PLgel (Polymer Laboratories) Mixed-A mixed bed columns $(20 \mu \mathrm{m}$, $300 \mathrm{~mm} \times 7.8 \mathrm{~mm}$ internal diameter(I.D.)) with a guard column. The columns were maintained at $45^{\circ} \mathrm{C}$. The mobile phase was THF at a flow rate of $0.65 \mathrm{~mL} \mathrm{~min}{ }^{-1}$; the injected volume was $150 \mu \mathrm{L}$.

The data obtained with MALS detectors were analysed with ASTRA software (Wyatt Technology) using a Zimm fit. All the calculations were performed on the assumption that particular elution volume slices were monodisperse or very narrow. In the Zimm fit method, $\mathrm{Kc} / \Delta R(\theta)$ is plotted against $\sin ^{2}(\theta / 2)$ (equation (15)) and a 1 st order polynomial fit is used [26,27].

$\frac{K c}{\Delta R(\theta)_{i}}=\frac{1}{M_{\mathrm{w} i}}+\frac{16 \pi^{2} n_{0}^{2}}{3 \lambda_{0}^{2}} \frac{\left\langle R_{\mathrm{g}}^{2}\right\rangle_{i}}{M_{\mathrm{w} i}} \sin ^{2}(\theta / 2)$

where, $\Delta R(\theta)$ is the Rayleigh ratio, i.e. the ratio of scattered and incident light intensity; $c$ is the solute concentration in $\mathrm{g} \mathrm{mL}^{-1}, K$ is an optical constant given by equation (16), $\theta$ is the scattering angle, $M_{\mathrm{w} i}$ and $R_{\mathrm{g} i}$ are, respectively, the weight-average molar mass and zaverage radius of gyration for elution slice $i$.

$K=\frac{4 \pi^{2} n_{0}^{2}}{N_{\mathrm{a}} \lambda_{0}^{4}}(\mathrm{~d} n / \mathrm{d} c)^{2}$

where $n_{0}$ is the refractive index of the solvent; $N_{\mathrm{A}}$ is Avogadro's number; $\lambda_{0}$ is the wavelength of the laser beam in a vacuum 


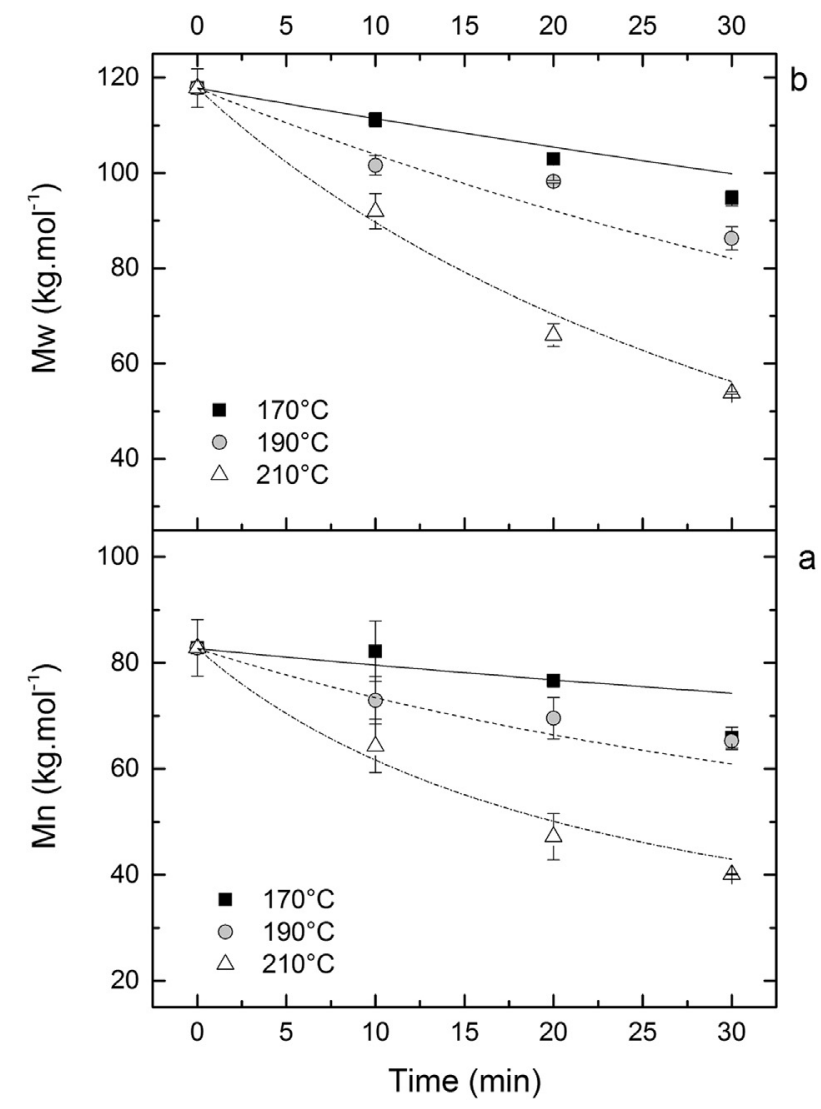

Fig. 1. Influence of time and temperature during processing by thermo-compression on (a) number-average and (b) weight-average molar masses for undried PLA. Lines represent the simulations $\left(170^{\circ} \mathrm{C}\right.$ : solid, $190^{\circ} \mathrm{C}$ : dashed, $210^{\circ} \mathrm{C}$ : dash-dot).

(633 $\mathrm{nm}$ for the Dawn DSP detector); and $\mathrm{d} n / \mathrm{d} c$ is the differential refractive index increment of the polymer in the solvent used. In the literature, the differential refractive index increment $(\mathrm{d} n / \mathrm{d} c)$ of PLA was determined at $0.042 \mathrm{~mL} \mathrm{~g}^{-1}$ [28], $0.049 \mathrm{~mL} \mathrm{~g}^{-1}$ [29] and $0.0558 \mathrm{~mL} \mathrm{~g}^{-1}$ [30]. In the case of the studied PLA, it was obtained by determining the refractive index of six solutions at different concentrations of PLA in THF using the Optilab refractometer (laser wavelength: $658 \mathrm{~nm}$ ). A value of $0.0496 \pm 0.0006 \mathrm{~mL} \mathrm{~g}^{-1}$ was obtained which is consistent with the values found in the literature.

\subsection{Temperature-modulated differential scanning calorimetry (TMDSC)}

A DSC Q200 (TA Instrument) equipped with a Refrigerated Cooling System (RCS) was used. Nitrogen gas with flow rate of

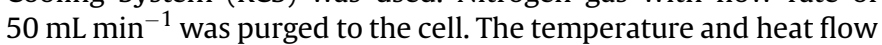
were calibrated by using indium as a standard. The calibration of the heat capacity was performed by using sapphire as a standard in the studied temperature range. Samples of about $15 \mathrm{mg}$ were packed down and sealed into aluminium DSC pans.

Prior to the heat capacity measurements, each sample was first maintained at $20^{\circ} \mathrm{C}$ for 5 min prior to be heated up to $220^{\circ} \mathrm{C}$. The heating rate was fixed at $\mathrm{q}=3{ }^{\circ} \mathrm{C} \mathrm{min}^{-1}$, the period of temperature oscillation was $P=100 \mathrm{~s}$ and its amplitude was $\mathrm{A}= \pm 0.796{ }^{\circ} \mathrm{C}$ in order to maintain an increasing temperature during the modulation. The measured heat capacity was deconvoluted into reversing and non-reversing components to separate thermodynamics and kinetics phenomena.

All experiments were performed in triplicate. The standard deviation of the results on the same sample was approximately $1{ }^{\circ} \mathrm{C}$ and $5 \%$ for temperature and enthalpy respectively.

\section{Results and discussion}

\subsection{Influence of processing conditions on PLA degradation assessed by molar mass measurements}

The initial number average- $\left(M_{n}\right)$ and weight average- $\left(M_{\mathrm{w}}\right)$ molar masses of the used PLA before processing are respectively $82.9 \pm 5.3 \mathrm{~kg} \mathrm{~mol}^{-1}$ and $117.8 \pm 4.1 \mathrm{~kg} \mathrm{~mol}^{-1}$. The polydispersity index $Q$ is $1.425 \pm 0.049$.

\subsubsection{Thermo-compression moulding}

4.1.1.1. Influence of temperature and time during processing on PLA degradation. In order to study only the effect of temperature and time during processing, undried PLA was first processed by thermocompression moulding. It was assumed that the mechanical input in thermo-compression is negligible compared to thermal batch mixing. An example of molar masses changes during processing at $210^{\circ} \mathrm{C}$ is given in Supporting data. Unprocessed PLA exhibits a lognormal distribution of molar mass. The form of the distribution was maintained during processing. The main difference consists in a shift of the distribution to lower molar mass values. Therefore it was decided in the following text to present only results related to average molar masses $M_{n}$ and $M_{\mathrm{w}}$. The reduction of $M_{n}$ and $M_{\mathrm{w}}$ during thermal treatment at different temperatures (170, 190 and $210{ }^{\circ} \mathrm{C}$ ) is shown in Fig. 1. Degradation occurs in a greater extent when the temperature increases and affects similarly both average molar masses. Besides, polydispersity index $Q$ remains constant around 1.4 with standard deviation lower than $6 \%$ (Table 1 ). It was observed by Yu et al. [2] that $Q$ increases with heating time up to 2 which is the asymptotic value in a random chain scission hypothesis. Nevertheless in this paper this value was reached for longer time (several hours). In our case, it was assumed that the degradation time was too short (only $30 \mathrm{~min}$ ) to give rise to a significant change in the $Q$ value.

The model for PLA degradation proposed by Wachsen et al. [15] considered a statistical process of chain scission that could describe hydrolysis, pyrolysis and transesterification reactions. It was used to model the effect of time on thermal degradation of undried PLA. The influence of temperature on both degradation $\left(k_{\mathrm{d}}\right)$ and

Table 1

Polydispersity index $Q$ for the various materials and the various processing conditions (standard deviation in brackets).

\begin{tabular}{|c|c|c|c|c|c|c|c|c|c|c|}
\hline \multirow{2}{*}{\multicolumn{2}{|c|}{$\begin{array}{l}\text { Materials } \\
\text { Temperature }\end{array}$}} & \multicolumn{6}{|c|}{ Undried PLA } & \multicolumn{3}{|l|}{ Dried PLA } \\
\hline & & \multicolumn{4}{|l|}{$170{ }^{\circ} \mathrm{C}$} & \multirow{2}{*}{$\frac{190^{\circ} \mathrm{C}}{0}$} & \multirow{2}{*}{$\frac{210^{\circ} \mathrm{C}}{0}$} & \multirow{2}{*}{$\frac{170{ }^{\circ} \mathrm{C}}{0}$} & \multirow{2}{*}{$\frac{190{ }^{\circ} \mathrm{C}}{0}$} & \multirow{2}{*}{$\frac{210^{\circ} \mathrm{C}}{0}$} \\
\hline Rotor speed & & 0 & 40 & 75 & 150 & & & & & \\
\hline \multirow[t]{4}{*}{ Time (min) } & 0 & $1.42(0.05)$ & $1.42(0.05)$ & $1.42(0.05)$ & $1.42(0.05)$ & $1.42(0.05)$ & $1.42(0.05)$ & $1.42(0.05)$ & $1.42(0.05)$ & $1.42(0.05)$ \\
\hline & 10 & $1.36(0.07)$ & $1.44(0.12)$ & $1.43(0.09)$ & $1.49(0.13)$ & $1.40(0.06)$ & $1.43(0.08)$ & $1.35(0.03)$ & $1.33(0.04)$ & $1.36(0.04)$ \\
\hline & 20 & $1.34(0.01)$ & $1.47(0.01)$ & $1.42(0.03)$ & $1.50(0.06)$ & $1.40(0.06)$ & $1.40(0.08)$ & $1.40(0.06)$ & $1.36(0.04)$ & $1.39(0.03)$ \\
\hline & 30 & $1.44(0.03)$ & $1.47(0.08)$ & $1.44(0.04)$ & $1.40(0.04)$ & $1.32(0.01)$ & $1.35(0.02)$ & $1.36(0.04)$ & $1.42(0.07)$ & $1.40(0.06)$ \\
\hline
\end{tabular}


Table 2

Activation energies ( $E_{\mathrm{ad}}$ and $\left.E_{\mathrm{ac}}\right)$ and pre-exponential factors $\left(A_{\mathrm{d}}\right.$ and $\left.A_{\mathrm{c}}\right)$ for undried PLA and dried PLA

\begin{tabular}{lllll}
\hline Material & $\begin{array}{l}E_{\mathrm{ad}} \\
\left(\mathrm{kJ} \mathrm{mol}^{-1}\right)\end{array}$ & $\begin{array}{l}A_{\mathrm{d}} \\
\left(10^{6} \mathrm{~s}^{-1}\right)\end{array}$ & $\begin{array}{l}E_{\mathrm{ac}} \\
\left(\mathrm{kJ} \mathrm{mol}^{-1}\right)\end{array}$ & $\begin{array}{l}A_{\mathrm{c}} \\
\left(10^{3} \mathrm{~L} \mathrm{~mol}^{-1} \mathrm{~s}^{-1}\right)\end{array}$ \\
\hline Wachsen et al. & $120 \pm 20$ & $7.1 \pm 0.3$ & $49 \pm 15$ & $2.2 \pm 0.2$ \\
Undried PLA & 87.2 & 1.6 & 37.7 & 121.6 \\
Dried PLA & 79.7 & 1.0 & 30.8 & 14.6 \\
\hline
\end{tabular}

${ }^{\text {a }}$ Data from Ref. [15].

recombination $\left(k_{\mathrm{c}}\right)$ rate constants was described with an Arrhenius law. The differential system of equations (equations (7)-(9)) was solved with Matlab ${ }^{\circledR}$ R2010a using a fourth order Runge-Kutta method. The optimization of the parameters was done using the least squares method, the residual being minimized with a Nelder-Mead simplex algorithm.

The activation energies for the degradation and recombination processes in the case of undried PLA are slightly lower than the values obtained by Wachsen et al. [15] (Table 2). If both degradation rate constants at $170{ }^{\circ} \mathrm{C}\left(k_{\mathrm{d}}\right)$ have the same order of magnitude, the recombination rate constant $\left(k_{\mathrm{c}}\right)$ is about a thousand times lower in Wachsen's work [15]. These discrepancies may be related to different experimental conditions (non-oxidant/oxidant atmosphere, purified grade/crude grade of PLA). Nevertheless, the model shows a good correlation (coefficient of determination $R^{2}$ near 1 ) with the experimental results for the average molar masses (Table 3).

4.1.1.2. Influence of PLA drying on PLA degradation. Fig. 2 shows the reduction of weight-average and number-average molar masses in the case of dried PLA for three temperatures $\left(170,190\right.$ and $\left.210{ }^{\circ} \mathrm{C}\right)$. The extent of degradation previously observed is significantly reduced after drying. For example, after $30 \mathrm{~min} 170{ }^{\circ} \mathrm{C}$, the numberaverage molar mass of undried PLA was decreased by $20.5 \%$ whereas the number-average molar mass reduction of dried PLA was only $3.1 \%$. For similar reasons as those given in 4.1.1.1, the polydispersity index $Q$ was almost unaffected by drying (Table 1 ). The degradation rate constant at $170{ }^{\circ} \mathrm{C}$ was divided by a factor 2 when PLA had been dried (Table 2). Kinetics parameters for PLA hydrolysis were studied under high pressure steam by MohdAdnan et al. [31]. Considering their values, i.e. an activation energy of $87.2 \mathrm{~kJ} \mathrm{~mol}^{-1}$ and a pre-exponential factor of $1.28 \times 10^{8} \mathrm{~s}^{-1}$, the rate constant for hydrolysis at $170{ }^{\circ} \mathrm{C}$ should be approximately $6.810^{-3} \mathrm{~s}^{-1}$ what is much higher than the obtained $k_{\mathrm{d}}$ value. Therefore it can be concluded that, in our conditions, hydrolysis remains a minor phenomenon.

Table 3 shows the coefficient of determination $R^{2}$ between experiments and simulations in the case of dried PLA. It can be seen that the correlation is weaker when PLA has been dried, particularly at $170{ }^{\circ} \mathrm{C}$. However it should be underlined that, at this temperature, the experimental variation of molar mass with is very low. Thus in this case $R^{2}$ has no real significance since the mean of the data provides a better fit than do the fitted function values.

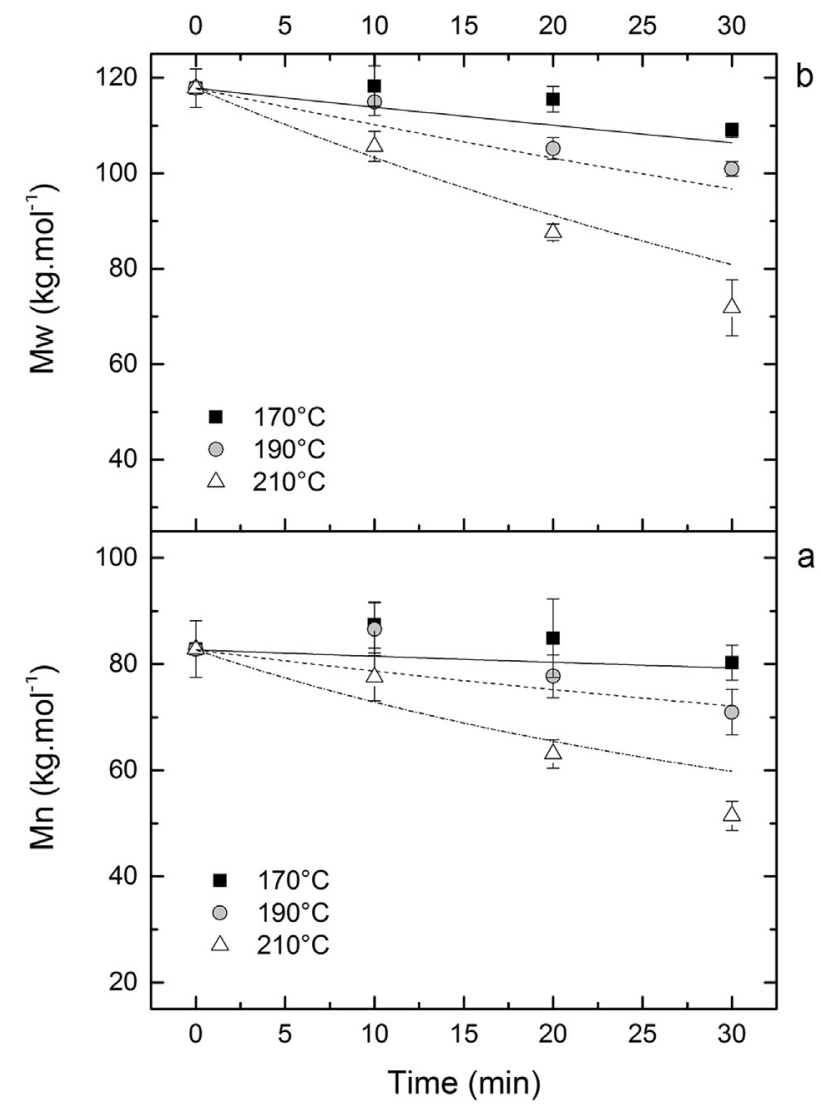

Fig. 2. Influence of time and temperature during processing by thermo-compression on (a) number-average and (b) weight-average molar masses for dried PLA. Lines represent the simulations $\left(170^{\circ} \mathrm{C}\right.$ : solid, $190^{\circ} \mathrm{C}$ : dashed, $210^{\circ} \mathrm{C}$ : dash-dot).

\subsubsection{Batch mixing}

4.1.2.1. Influence of rotor speed on PLA degradation. The evolution of torque and polymer temperature during batch mixing of undried PLA for two rotor speeds (40 and $150 \mathrm{rpm}$ ) and two mixing set temperatures ( 170 and $190^{\circ} \mathrm{C}$ ) is shown in Fig. 3. It is observed that an increasing rotor speed will accelerate the transient phase (i.e. peak corresponding to the melting of pellets) without affecting the torque in steady-state. It also increases the polymer temperature due to higher viscous dissipation. An increasing set temperature will also accelerate the transient phase but it reduces the torque in steady-state because of a lower viscosity of the material. It also increases the polymer temperature but the self-heating (difference between polymer and set mixing temperature) decreases, the viscous dissipation being also reduced.

The evolution of the specific mechanical energy (SME) and of the self-heating of undried PLA after a mixing time of $10 \mathrm{~min}$ in a batch mixing system as a function of the rotor speed for two mixing set temperatures ( 170 and $190^{\circ} \mathrm{C}$ ) is presented in Fig. 4. The correlation between SME and temperature elevation is obvious. A higher mixing

Table 3

Coefficient of determination $\mathrm{R}^{2}$ between experimental results and simulations for the various materials and the various processing conditions.

\begin{tabular}{|c|c|c|c|c|c|c|c|c|c|c|}
\hline \multirow{2}{*}{\multicolumn{2}{|c|}{$\begin{array}{l}\text { Materials } \\
\text { Temperature }\end{array}$}} & \multicolumn{6}{|c|}{ Undried PLA } & \multicolumn{3}{|c|}{ Dried PLA } \\
\hline & & \multicolumn{4}{|l|}{$170^{\circ} \mathrm{C}$} & \multirow{2}{*}{$\frac{190^{\circ} \mathrm{C}}{0}$} & \multirow{2}{*}{$\frac{210^{\circ} \mathrm{C}}{0}$} & \multirow{2}{*}{$\frac{170^{\circ} \mathrm{C}}{0}$} & \multirow{2}{*}{$\frac{190^{\circ} \mathrm{C}}{0}$} & \multirow{2}{*}{$\frac{210^{\circ} \mathrm{C}}{0}$} \\
\hline & & 0 & 40 & 75 & 150 & & & & & \\
\hline \multirow[t]{2}{*}{$R^{2}$} & $M_{\mathrm{n}}$ & 0.814 & 0.974 & 0.989 & 0.878 & 0.981 & 0.983 & 0.159 & 0.656 & 0.913 \\
\hline & $M_{\mathrm{w}}$ & 0.991 & 0.986 & 0.982 & 0.903 & 0.961 & 0.974 & 0.751 & 0.947 & 0.975 \\
\hline
\end{tabular}




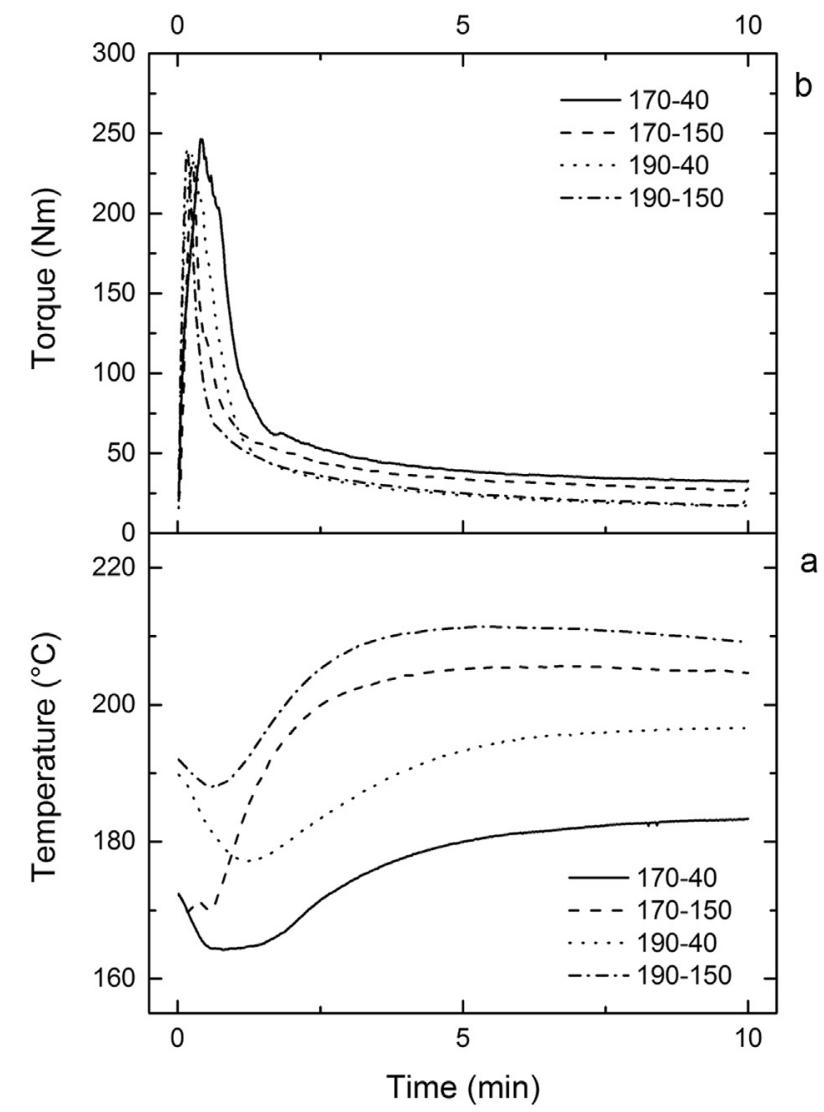

Fig. 3. Evolution of (a) torque and (b) polymer temperature of undried PLA for different batch mixing parameters: mixing temperature $\left(170\right.$ or $\left.190^{\circ} \mathrm{C}\right)$ - rotor speed (40 or $150 \mathrm{rpm}$ ).

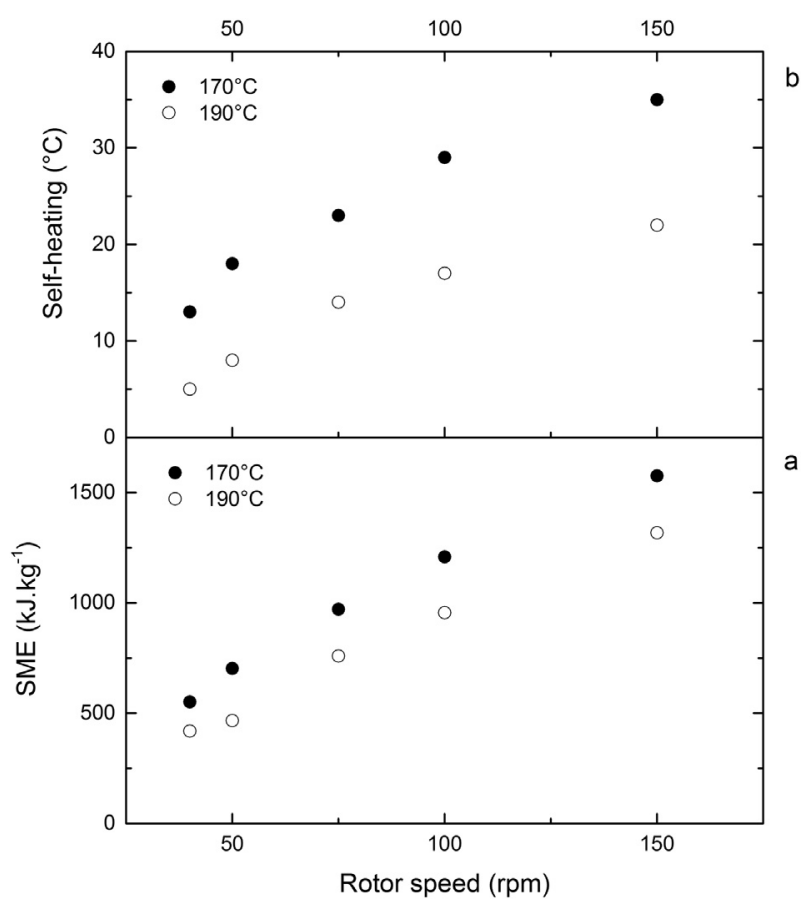

Fig. 4. Influence of processing parameters on (a) SME and (b) self-heating after a mixing time of $10 \mathrm{~min}$ in a batch mixing system. temperature decreases the viscosity and then decreases the mechanical energy requirement for the rotor rotation. Thus, the viscous dissipation is also lowered and the self-heating is reduced.

The evolution of the weight-average and number-average molar masses with mixing time of undried PLA in a batch mixing system for different rotor speeds and a given mixing set temperature of $170{ }^{\circ} \mathrm{C}$ was observed on Fig. 5 . It is demonstrated that the extent of degradation of PLA increases with increasing rotor speed.

The two average molar masses are similarly affected by this mechanical input while the polydispersity index remains once again quasi unchanged (Table 1). For a given set temperature, the reduction of molar mass with an increasing rotor speed (equivalent to shear rate) can be explained by the viscous dissipation converted into heat. The effective temperature of the polymer $T_{\mathrm{p}}$ is not the set temperature but the set temperature plus self-heating as revealed by Fig. 3a. To correctly take into account both mechanical (i.e. rotor speed) and thermal (i.e. mixing set temperature) energy input in modelling of molar mass variation, the degradation kinetics during a test performed at a set temperature $T$ and a rotor speed $\omega$ have been described using the effective temperature of the matter $T_{\mathrm{p}}(T$, $\omega$ ) in Arrhenius laws (equations (4) and (5)).

The values of self-heating that were taken in calculations were those presented in Fig. 4. Fitted curves for undried PLA mixing at $170^{\circ} \mathrm{C}$ are plotted in Fig. 5 together with experimental data. Table 3 shows the coefficient of determination $R^{2}$ between experimental results and simulation. The correlation is rather good for both average molar masses. In conclusion, the simulation of degradation during mixing seems to be efficient when considering the selfheating due to viscous dissipation.

4.1.2.2. Influence of temperature on PLA degradation. Fig. 6 shows the weight-average molar mass reduction for a mixing time of 10 min using different rotor speeds $(40,50,75,100,150 \mathrm{rpm})$ and mixing temperatures $\left(170\right.$ and $\left.190^{\circ} \mathrm{C}\right)$. In these cases, the simulation underestimates the extent of degradation. This was attributed to the degradation occurring also during cooling process. Indeed, when it lasts only $10 \mathrm{~min}$, the mixing time is not sufficient to explain the whole degradation and the cooling phase (between 10 and $20 \mathrm{~min}$ depending on the mixing parameters) must be taken into account.

Fig. 7 shows the evolution of weight-average molar mass with steady-state temperature after a mixing time of $10 \mathrm{~min}$ of undried PLA for two mixing set temperatures of $170^{\circ} \mathrm{C}$ and $190{ }^{\circ} \mathrm{C}$. Simulated curves are also plotted for three different mixing times (10, 20 and $30 \mathrm{~min}$ ). It can be seen that the experimental results deviate from the 10 min simulated curve especially at high mixing set temperatures to move closer to the 20 min simulated curve. As the duration of the cooling process is also longer when the temperature is higher, it confirms the previous assumption of an additional degradation process occurring during cooling. However, due to the difficulties to set up an accurate and reproducible measurement of the polymer temperature during the cooling phase, it was not possible to take it into account in the simulation.

4.1.2.3. Influence of PLA drying on PLA degradation. Fig. 8 shows a comparison of molar mass reduction for dried and undried PLA when mixing was performed at $40 \mathrm{rpm}$ and $170{ }^{\circ} \mathrm{C}$. The results confirm the trend observed in the absence of shear. Drying enables limiting chain scission. Hence, after 30 min mixing, the molar mass decrease was only $19 \%$ against $28 \%$ for undried PLA.

\subsection{Influence of degradation during processing on PLA crystallization}

The influence of molar mass reduction induced by different processing conditions using thermo-compression moulding (data 


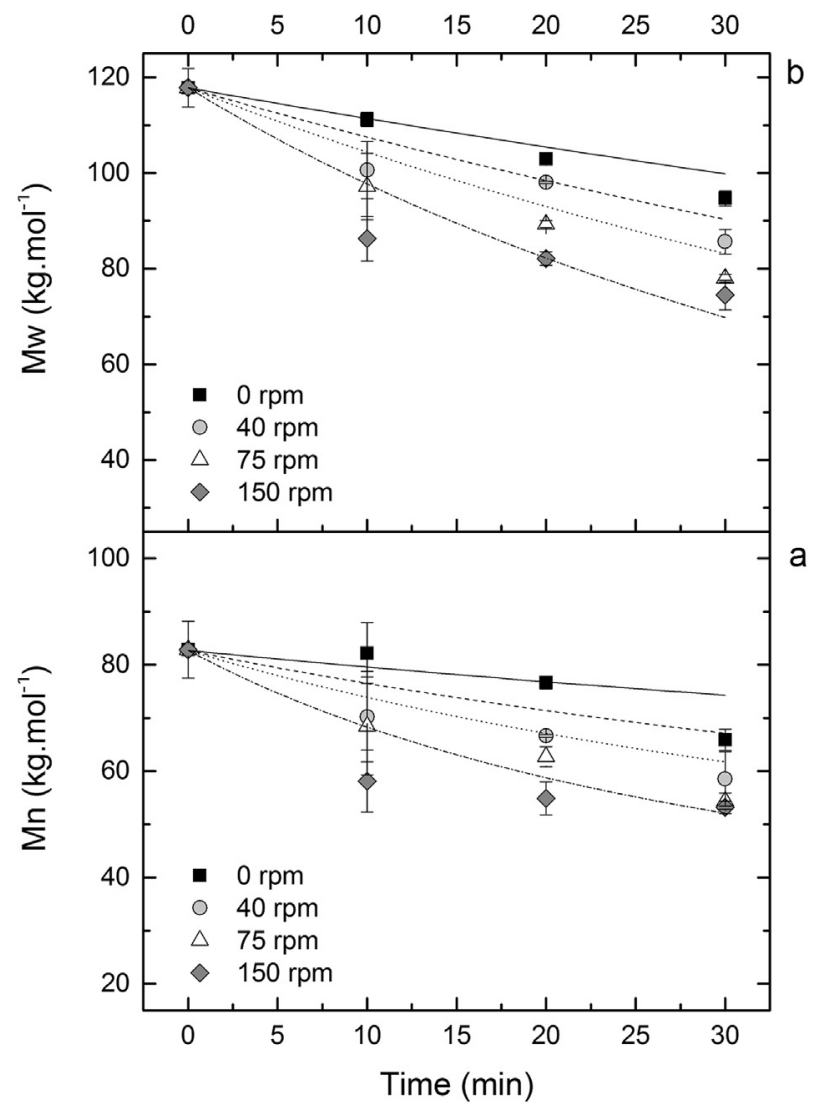

Fig. 5. Influence of rotor speed and mixing time at $170{ }^{\circ} \mathrm{C}$ on (a) number-average and (b) weight-average molar masses. Lines correspond to the simulation using the steadystate temperature and the constants determined for undried PLA $(0 \mathrm{rpm}$ : solid, $40 \mathrm{rpm}$ : dashed, $75 \mathrm{rpm}$ : doted, $150 \mathrm{rpm}$ : dash-dot).

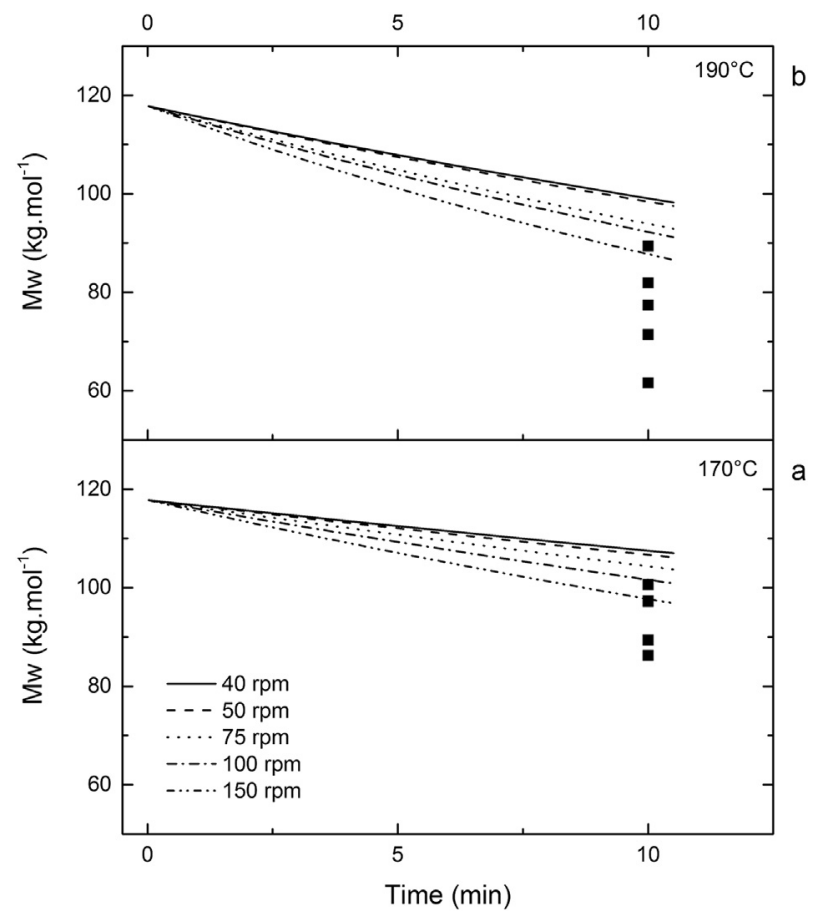

Fig. 6. Influence of set temperature $\left((\mathrm{a})\right.$ at $170^{\circ} \mathrm{C}$ and $(\mathrm{b})$ at $\left.190{ }^{\circ} \mathrm{C}\right)$ on weight-average molar masses for a mixing time of $10 \mathrm{~min}$ and various rotor speeds. Lines represent the corresponding simulations.

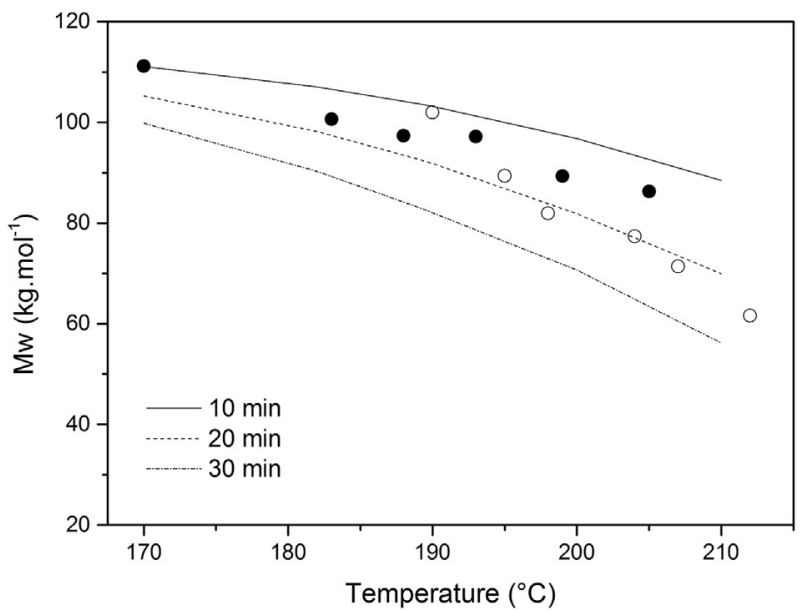

Fig. 7. Influence of steady-state temperature on weight-average molar mass after 10 min mixing at various set temperature $\left(\bullet 170{ }^{\circ} \mathrm{C}\right.$, fx $\left.1190^{\circ} \mathrm{C}\right)$ and various rotor speed. Lines represent the simulations for a mixing time of 10 (solid), 20 (dashed) and $30 \mathrm{~min}$ (dash-dot) at the corresponding steady-state temperature.

obtained with $0 \mathrm{rpm}$ ) and batch mixing on the thermal behaviour of PLA was studied by TMDSC.

For unprocessed PLA pellets, glass transition $T_{\mathrm{g}}$ occurs at $57.7{ }^{\circ} \mathrm{C}$ and a melting temperature $T_{\mathrm{m}}$ is found at $150.8^{\circ} \mathrm{C}$ what is close to supplier data $[20,21]$. No crystallization peak is observed during the heating ramp because the pellets were already crystallized during

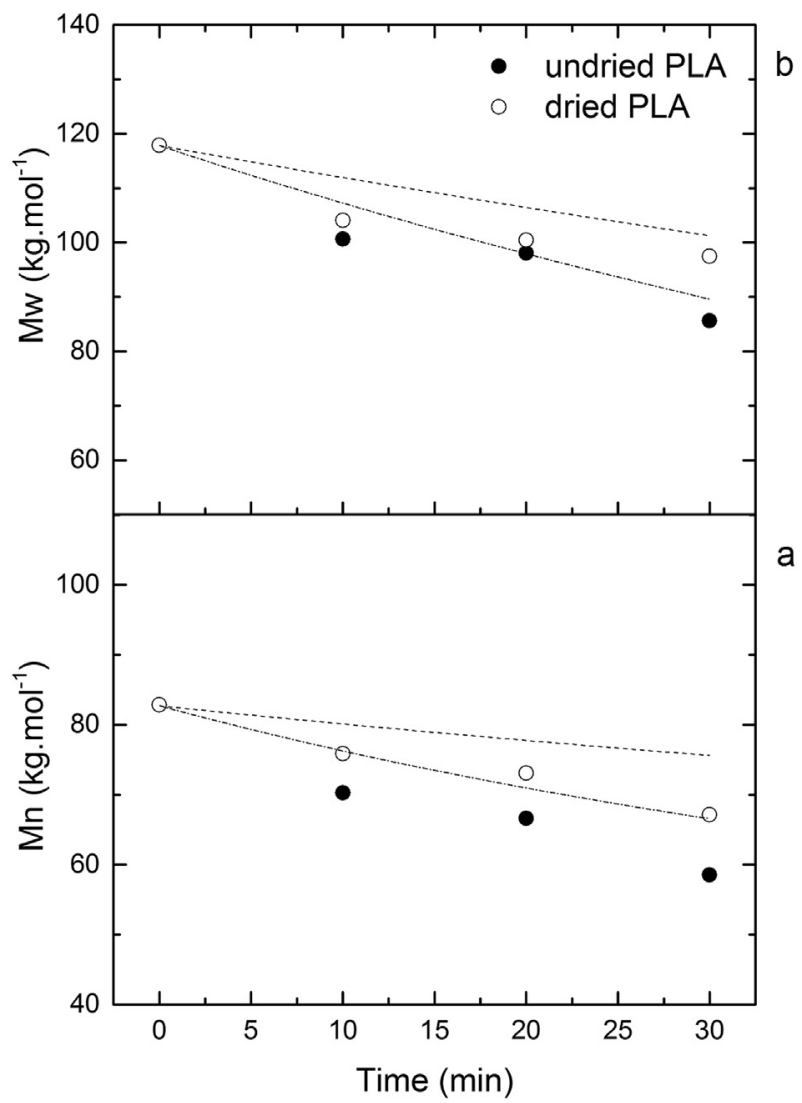

Fig. 8. Influence of drying on (a) number-average and (b) weight-average molar masses at $170{ }^{\circ} \mathrm{C}$ and $40 \mathrm{rpm}$. Lines represent the simulations using the steady-state temperature and the constants determined for dried (dashed) and undried PLA (dash-dot). 


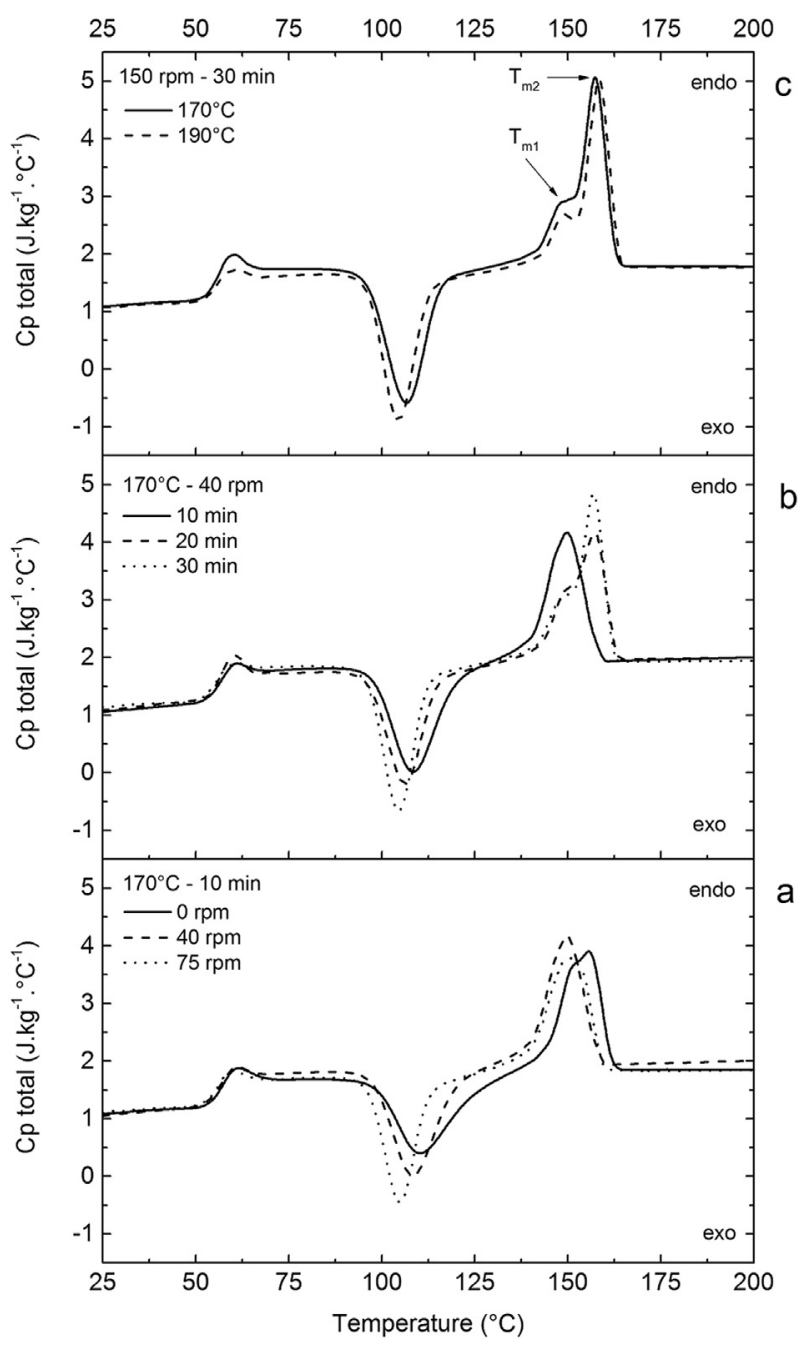

Fig. 9. Influence of processing parameters on heat capacity of PLA: (a) rotor speed ( 0 , 40 and $75 \mathrm{rpm}$ ) at $170^{\circ} \mathrm{C}$ for $10 \mathrm{~min}$, (b) time $\left(10,20\right.$ and $30 \mathrm{~min}$ ) at $170^{\circ} \mathrm{C}$ and $40 \mathrm{rpm}$ and (c) temperature $\left(170\right.$ and $\left.190{ }^{\circ} \mathrm{C}\right)$ at $150 \mathrm{rpm}$ for $30 \mathrm{~min}$.

manufacturing. The melting enthalpy $\Delta \mathrm{H}_{\mathrm{m}}$ is estimated at $34.7 \mathrm{~kJ} \mathrm{~kg}^{-1}$ corresponding to a crystallinity of $37 \%$ considering that the melting enthalpy of $100 \%$ crystalline polymer is $93 \mathrm{~kJ} \mathrm{~kg}^{-1}$ [32].

Fig. 9 and Table 4 present respectively the evolution of heat capacity of PLA obtained after different processing conditions and the values of the different temperatures and enthalpies $\left(T_{\mathrm{g}}\right.$ for glass transition temperature, $T_{\mathrm{c}}$ and $\Delta H_{\mathrm{c}}$ for crystallization temperature and enthalpy, $T_{\mathrm{m} 1}, T_{\mathrm{m} 2}$ and $\Delta H_{\mathrm{m}}$ for both melting temperatures and

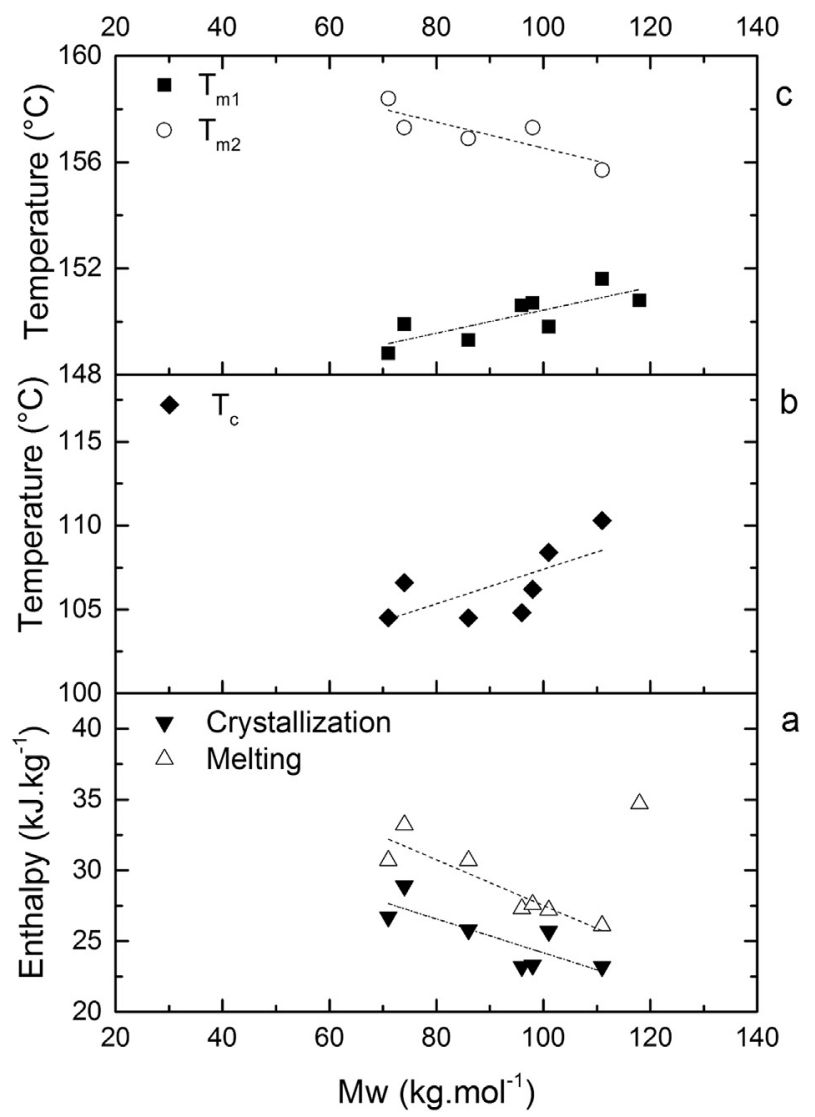

Fig. 10. Variation of (a) crystallization and melting enthalpies, (b) cold crystallization temperature and (c) melting temperatures as a function of molar masses.

total melting enthalpy) in relation with the previously determined weight-average molar mass.

It can be observed on one hand that glass transition is not really affected by processing with values around $56{ }^{\circ} \mathrm{C}$ whatever the processing conditions.

On the other hand it appears that the crystallization temperature decreases with increasing rotor speed (for example for $170{ }^{\circ} \mathrm{C}-10 \mathrm{~min}$ processing conditions, $T_{\mathrm{C}}$ decreases from $110.3^{\circ} \mathrm{C}$ to $104.8^{\circ} \mathrm{C}$ with an increased rotor speed from 0 to $75 \mathrm{rpm}$ ), mixing time (for example for $170{ }^{\circ} \mathrm{C}-40 \mathrm{rpm}$ processing conditions, $T_{\mathrm{C}}$ decreases from $108.4{ }^{\circ} \mathrm{C}$ to $104.5^{\circ} \mathrm{C}$ with an increased mixing time from 10 to $30 \mathrm{~min}$ ) and mixing temperature (for example for $150 \mathrm{rpm}-30 \mathrm{~min}$ processing conditions, $T_{\mathrm{c}}$ decreases from $106.6^{\circ} \mathrm{C}$ to $104.5{ }^{\circ} \mathrm{C}$ with increasing mixing temperature from $170{ }^{\circ} \mathrm{C}$ to $190{ }^{\circ} \mathrm{C}$ ) as shown on Fig. 9.

Table 4

Transition temperature and enthalpies after different processing conditions.

\begin{tabular}{|c|c|c|c|c|c|c|c|c|c|}
\hline Temperature $\left({ }^{\circ} \mathrm{C}\right)$ & Rotor speed (rpm) & Time (min) & $M_{\mathrm{w}}\left(\mathrm{kg} \mathrm{mol}^{-1}\right)$ & $T_{\mathrm{g}}\left({ }^{\circ} \mathrm{C}\right)$ & $T_{\mathrm{c}}\left({ }^{\circ} \mathrm{C}\right)$ & $\Delta \mathrm{H}_{\mathrm{c}}\left(\mathrm{kJ} \mathrm{kg}^{-1}\right)$ & $T_{\mathrm{m} 1}\left({ }^{\circ} \mathrm{C}\right)$ & $T_{\mathrm{m} 2}\left({ }^{\circ} \mathrm{C}\right)$ & $\Delta \mathrm{H}_{\mathrm{m}}\left(\mathrm{kJ} \mathrm{kg}^{-1}\right)$ \\
\hline- & - & - & 118 & 57.7 & - & - & 150.8 & - & 34.7 \\
\hline 170 & - & 10 & 111 & 57.2 & 110.3 & 23.2 & 151.6- & 155.7 & 26.1 \\
\hline 170 & 40 & 10 & 101 & 56.7 & 108.4 & 25.7 & 149.8 & - & 27.2 \\
\hline 170 & 75 & 10 & 96 & 56.2 & 104.8 & 23.2 & 150.6 & - & 27.3 \\
\hline 170 & 150 & 10 & 86 & & & & & & \\
\hline 170 & 40 & 20 & 98 & 57.4 & 106.2 & 23.3 & 150.7 & 157.3 & 27.6 \\
\hline 170 & 40 & 30 & 86 & 56.3 & 104.5 & 25.8 & 149.3 & 156.9 & 30.7 \\
\hline 170 & 75 & 30 & 78 & & & & & & \\
\hline 170 & 150 & 30 & 74 & 56.8 & 106.6 & 28.9 & 149.9 & 157.3 & 33.2 \\
\hline 190 & 150 & 30 & 71 & 55.6 & 104.5 & 26.7 & 148.8 & 158.4 & 30.7 \\
\hline
\end{tabular}




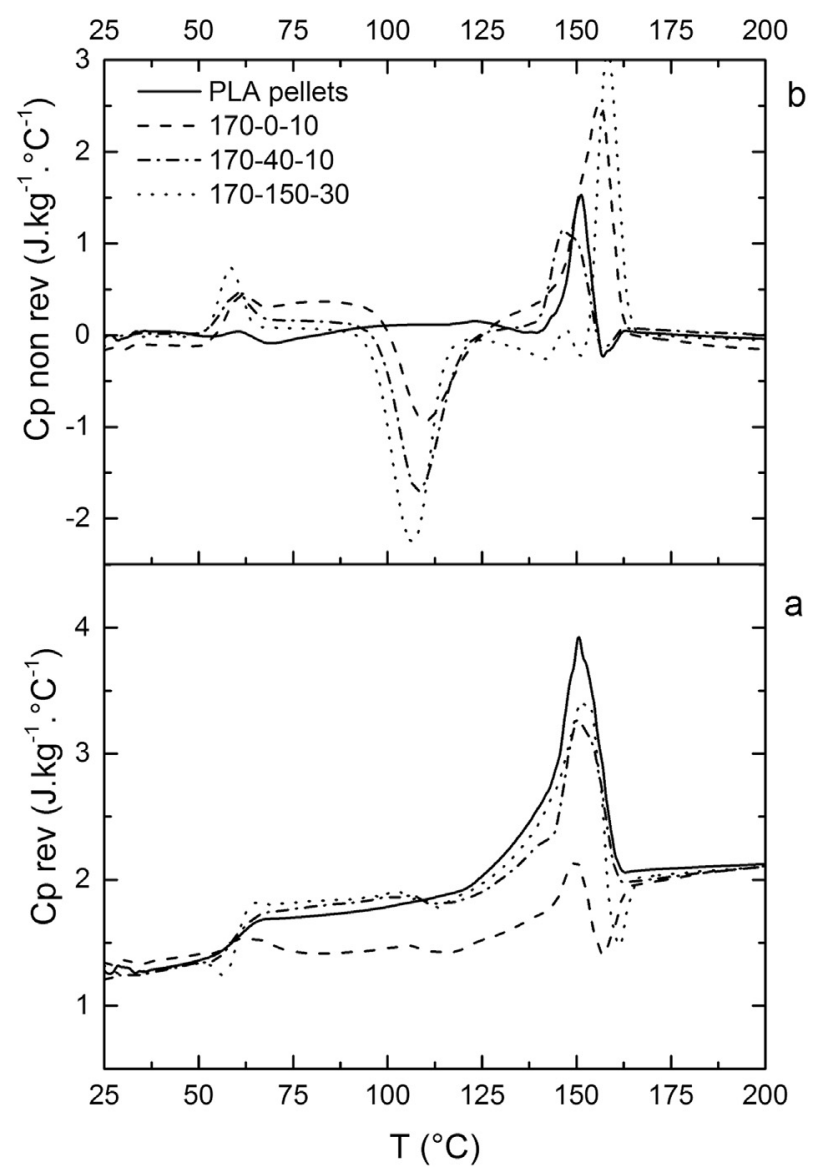

Fig. 11. (a) reversing and (b) non-reversing heat capacity of PLA after different processing conditions.

Fig. 10 presents the variation of crystallization and melting temperatures and enthalpies as a function of weight-average molar mass $\left(M_{\mathrm{w}}\right)$. The curves indicate that crystallization occurs at lower temperature and in a greater extent (increase of enthalpy) as the weight-average molar mass decreases. Moreover, it can be observed on Fig. 9 that the crystallization rate increases also with decreasing $M_{\mathrm{w}}$ as proved by the increase of crystallization peak height. All these results show that the reduction of the chain length during processing promotes subsequent crystallizability of PLA. This could be assigned to an increase of molecular mobility which can result either in an increase of nucleation rate during cooling or to an increase of growth rate during re-heating. Thus, crystallizability seems to be mainly governed by the molar mass whatever the processing conditions.

The melting behaviour is more complicated since two melting temperatures $\left(T_{\mathrm{m} 1}\right.$ and $\left.T_{\mathrm{m} 2}\right)$ are observed. Fig. 9a shows that after a short time of mixing (10 min), PLA melting occurs at the same temperature than for the virgin pellets, i.e. around $150{ }^{\circ} \mathrm{C}$. However it should be noticed that PLA obtained by thermo-compression moulding ( $170{ }^{\circ} \mathrm{C}-0 \mathrm{rpm}-10 \mathrm{~min}$ ) exhibits a second melting peak at higher temperature. Fig. $9 \mathrm{~b}$ shows that when mixing time increases the magnitude of first melting peak located around $150^{\circ} \mathrm{C}$ decreases and a second melting arises $10{ }^{\circ} \mathrm{C}$ higher. Fig. 9c shows that the effect of a higher processing temperature is similar to a longer processing time with the appearance of a second melting peak. Fig. 10c reveals that the position of melting peaks $\left(T_{\mathrm{m} 1}\right.$ and $T_{\mathrm{m} 2}$ ) is closely related to the weight-average molar mass. When $M_{\mathrm{w}}$ decreases $T_{\mathrm{m} 1}$ decreases while $T_{\mathrm{m} 2}$ increases.

Yasuniwa et al. [33] observed this double melting behaviour when studying the non-isothermal crystallization behaviour of PLA $\left(M_{\mathrm{w}}=300000 \mathrm{~g} \mathrm{~mol}^{-1}\right)$ at various cooling rates (melt crystallized samples) and heating rates (cold crystallized samples). Depending on both cooling and heating rates, when melt crystallized samples were heated, they observed a double melting peak around 175 and $180^{\circ} \mathrm{C}$, which was explained by a melt-recrystallization process. In latter works concerning isothermally crystallized PLA [34-36], they only observed the double melting behaviour for crystallization temperature below $113^{\circ} \mathrm{C}$. In this case, X-ray diffraction patterns showed a phase transition from a low temperature crystal ( $\alpha^{\prime}$-form) to a high-temperature one ( $\alpha$-form).

The most common $\alpha$-form has a pseudo-orthorhombic unit cell ( $a=10.6 \AA, b=6.1$ or $6.5 \AA, c=28.8$ or $27.8 \AA$ ) containing 2 chains, (left handed 10/3 helices) [37-42]. Zhang et al. [43] observed the disordered phase of $\alpha$-form ( $\alpha^{\prime}$-form) when PLA is crystallized below $120{ }^{\circ} \mathrm{C}$ and found that it has the same conformation but a loose packing manner. For PLA with $M_{\mathrm{W}}=206000 \mathrm{~g} \mathrm{~mol}^{-1}$, Kawai et al. [44] found that the $\alpha^{\prime}$-form has a pseudo-hexagonal unit cell ( $a=b=6.2 \AA, c=28.8 \AA$ ) and showed that a "pure" $\alpha^{\prime}$-form can only be obtained at crystallization temperature below $90{ }^{\circ} \mathrm{C}$. They also showed that a phase transition from $\alpha^{\prime}$ to $\alpha$ occurs above $150^{\circ} \mathrm{C}$ at a heating rate of $10^{\circ} \mathrm{C} / \mathrm{min}$ and is completed within $1.5 \mathrm{~min}$. This suggests a solid-solid phase transition instead of a meltrecrystallization process which should be much slower. Pan et al. [45] studied the influence of molar mass and crystallization temperature on the crystallization and melting behaviour of PLA. They observed that the crystallization rate greatly decreases with an increasing molar mass which shifts the non-isothermal cold crystallization peak toward higher temperature. For samples crystallized below $100{ }^{\circ} \mathrm{C}$, they also observed a complete phase transition of $\alpha^{\prime}$ crystals into $\alpha$ crystals during melting for high molar mass PLA whereas only partial phase transition of $\alpha^{\prime}$ crystals occurs for low molar mass PLA. With increasing crystallization temperatures (from 100 to $130{ }^{\circ} \mathrm{C}$ ), they observe a change from phase transition to melt-recrystallization mechanism. Above $130{ }^{\circ} \mathrm{C}$, they only observe the pure $\alpha$-form.

In the present study, it has been shown in Fig. 10b that the cold crystallization temperature decreases as the extent of degradation advances, i.e. as molar mass decreases. Thus, degradation favours the formation of the $\alpha^{\prime}$-form at the expense of $\alpha$-form. When heated, the $\alpha^{\prime}$-form exhibits melt-recrystallization leading to the double melting peak.

In order to analyse in more details the double-melting behaviour, heat capacity is deconvoluted into its reversing and nonreversing components (Fig. 11). Table 5 presents the different

Table 5

Transition temperatures and enthalpies from reversing and non-reversing heat capacity signal after different processing conditions.

\begin{tabular}{|c|c|c|c|c|c|c|c|c|c|c|c|c|}
\hline \multirow{2}{*}{$\begin{array}{l}\text { Temperature } \\
\left({ }^{\circ} \mathrm{C}\right)\end{array}$} & \multirow{2}{*}{$\begin{array}{l}\text { Rotor speed } \\
(\mathrm{rpm})\end{array}$} & \multirow{2}{*}{$\begin{array}{l}\text { Time } \\
(\min )\end{array}$} & \multicolumn{3}{|c|}{ Reversing } & \multicolumn{7}{|l|}{ Non-reversing } \\
\hline & & & $T_{\mathrm{g}}\left({ }^{\circ} \mathrm{C}\right)$ & $T_{\mathrm{m} 1}\left({ }^{\circ} \mathrm{C}\right)$ & $\Delta H_{\mathrm{m} 1}\left(\mathrm{~kJ} \mathrm{~kg}^{-1}\right)$ & $\Delta H_{\mathrm{Tg}}\left(\mathrm{kJ} \mathrm{kg}^{-1}\right)$ & $T_{\mathrm{c}}\left({ }^{\circ} \mathrm{C}\right)$ & $\Delta H_{\mathrm{c}}\left(\mathrm{kJ} \mathrm{kg}^{-1}\right)$ & $T_{\mathrm{m} 1}\left({ }^{\circ} \mathrm{C}\right)$ & $\Delta H_{\mathrm{m} 1}\left(\mathrm{~kJ} \mathrm{~kg}^{-1}\right)$ & $T_{\mathrm{m} 2}\left({ }^{\circ} \mathrm{C}\right)$ & $\Delta H_{\mathrm{m} 2}\left(\mathrm{~kJ} \mathrm{~kg}^{-1}\right)$ \\
\hline- & - & - & 59.9 & 150.6 & 27.5 & 0.6 & - & - & 150.8 & 8.2 & - & - \\
\hline 170 & - & 10 & 56.1 & 150.0 & 10.7 & 2.4 & 110.0 & 20.8 & - & - & 156.2 & 27.2 \\
\hline 170 & 40 & 10 & 59.2 & 150.2 & 19.4 & 2.8 & 108.0 & 25.3 & 147.9 & 12.2 & - & - \\
\hline 170 & 150 & 30 & 60.2 & 151.2 & 18.8 & 4.8 & 106.5 & 27.0 & 147.2 & 1.3 & 158.2 & 18.8 \\
\hline
\end{tabular}


transition temperatures and enthalpies obtained from both reversing and non-reversing signals. It appears that the first melting peak is mainly reversible and that the second melting peak is non-reversible. Since the $\alpha$-form is the most ordered phase, it may be assumed that it exhibits the higher melting peak $\left(157^{\circ} \mathrm{C}\right)$. This melting temperature is close to $166^{\circ} \mathrm{C}$ which is the equilibrium melting temperature of a $6 \%$ D-isomer containing PLA as determined by Baratian et al. [46]. Therefore recrystallization cannot occur because undercooling is low and thus complete melting of this phase appears on the non-reversing signal. On the contrary, the $\alpha^{\prime}$-form is a more disordered phase with a lower melting peak $\left(150^{\circ} \mathrm{C}\right)$. Undercooling is higher enabling recrystallization and thus melting comes out on the reversing signal.

\section{Conclusion}

The degradation of poly(lactic acid) (PLA) under various processing conditions has been studied using size-exclusion chromatography and temperature modulated differential scanning calorimetry. PLA degradation was highlighted to be mainly dependent on mixing time and temperature including self-heating due to the viscous dissipation induced by the rotor rotation. The real material temperature was taken into account to model the molar mass reduction using a statistical description of the degradation processes. The influence of PLA drying was also observed and it appears that drying decreases the degradation rate constant with a factor 2 .

The influence of degradation on the thermal properties was also studied. It appears that chain scission increases the molecular mobility, thus promoting cold crystallization at lower temperature. The crystallinity as well as the crystallization rate were proved to be enhanced. The melting behaviour is also modified and in some cases, a double-melting peak occurs. Temperature modulated DSC was used to separate those two peaks, it appears that the first melting peak is mainly reversible whereas the second one is totally non-reversible. This phenomenon was linked to phase transition between a metastable crystalline $\alpha^{\prime}$-form to the stable crystalline $\alpha$ form. Further analyses have to be done for a better understanding of this process.

\section{Appendix A. Supplementary data}

Supplementary data related to this article can be found at http:// dx.doi.org/10.1016/j.polymdegradstab.2014.10.003.

\section{References}

[1] Södergård A, Stolt M. Properties of lactic acid based polymers and their correlation with composition. Prog Polym Sci 2002;27:1123-63.

[2] Yu H, Huang N, Wang C, Tang Z. Modeling of poly(L-lactide) thermal degradation: theoretical prediction of molecular weight and polydispersity index. J Appl Polym Sci 2003;88:2557-62.

[3] Kopinke FD, Remmler M, Mackenzie K, Möder M, Wachsen O. Thermal decomposition of biodegradable polyesters - II. Poly(lactic acid). Polym Degrad Stabil 1996;53:329-42.

[4] Taubner V, Shishoo R. Influence of processing parameters on the degradation of poly(L-lactide) during extrusion. J Appl Polym Sci 2001;79:2128-35.

[5] Gogolewski S, Mainil-Varlet P. The effect of thermal treatment on sterility, molecular and mechanical properties of various polylactides. I. Poly(L-lactide). Biomaterials 1996;17:523-8.

[6] Gogolewski S, Javanovic M, Perren SM. The effect of melt-processing on the degradation of selected polyhydroxyacids: polylactides, polyhydroxybutyrate, and polyhydroxybutyrate-co-valerates. Polym Degrad Stabil 1993;40:313-22.

[7] Carrasco F, Pagès P, Gámez-Pérez J, Santana OO, Maspoch ML. Processing of poly(lactic acid): characterization of chemical structure, thermal stability and mechanical properties. Polym Degrad Stabil 2010;95:116-25.

[8] Gupta MC, Deshmukh VG. Thermal oxidative degradation of poly-lactic acid. Part II: molecular weight and electronic spectra during isothermal heating. Coll Polym Sci 1982;260:514-7.

[9] Jamshidi K, Hyon SH, Ikada Y. Thermal characterization of polylactides. Polymer 1988;29:2229-34.
[10] Signori F, Coltelli MB, Bronco S. Thermal degradation of poly(lactic acid) (PLA) and poly(butylene adipate-co-terephthalate) (PBAT) and their blends upon melt processing. Polym Degrad Stabil 2009;94:74-82.

[11] Hyon SH, Jamshidi K, Ikada Y. Effects of residual monomer on the degradation of DL-lactide polymer. Polym Int 1998;46:196-202.

[12] McNeill IC, Leiper HA. Degradation studies of some polyesters and polycarbonates-1. Polylactide: general features of the degradation under programmed heating conditions. Polym Degrad Stabil 1985;11:267-85.

[13] McNeill IC, Leiper HA. Degradation studies of some polyesters and polycarbonates-2. Polylactide: degradation under isothermal conditions, thermal degradation mechanism and photolysis of the polymer. Polym Degrad Stabil 1985;11:309-26.

[14] Wachsen O, Reichert KH, Krüger RP, Much H, Schulz G. Thermal decomposition of biodegradable polyesters - III. Studies on the mechanisms of thermal degradation of oligo-L-lactide using SEC, LACCC and MALDI-TOF-MS. Polym Degrad Stabil 1997:55:225-31.

[15] Wachsen O, Platkowski K, Reichert KH. Thermal degradation of poly-l-lactide -studies on kinetics, modelling and melt stabilisation. Polym Degrad Stabil 1997; 57:87-94.

[16] Wang Y, Steinhoff B, Brinkmann C, Alig I. In-line monitoring of the thermal degradation of poly(l-lactic acid) during melt extrusion by UV-vis spectroscopy. Polymer 2008;49(5):1257-65.

[17] Pillin I, Montrelay N, Bourmaud A, Grohens Y. Effect of thermo-mechanical cycles on the physico-chemical properties of poly(lactic acid). Polym Degrad Stabil 2008;93:321-8.

[18] Badia JD, Strömberg E, Karlsson S, Ribes-Greus A. Material valorisation of amorphous polylactide. Influence of thermo-mechanical degradation on the morphology, segmental dynamics, thermal and mechanical performance. Polym Degrad Stabil 2012;97:670-8.

[19] Staggs JEJ. Modelling end-chain scission and recombination of linear polymers. Polym Degrad Stabil 2004;85:759-67.

[20] NatureWorks LLC, NatureWorks ${ }^{\circledR}$ PLA polymer 7000D, [Technical Datasheet]

[21] Moldflow Plastics Labs. Moldflow material testing report, MAT2238, NatureWorks PLA 7000D. 2007.

[22] Bousmina M, Ait-Kadi A, Faisant JB. Determination of shear rate and viscosity from batch mixer data. J Rheol 1999;43(2):415-33.

[23] Cheng B, Zhou C, Yu W, Sun X. Evaluation of rheological parameters of polymer melts in torque rheometers. Polym Test 2001;20:811-8.

[24] Santi CR, Hage E, Correa CA, Vlachopoulos J. Torque viscosimetry of molten polymers and composites. Appl Rheol 2009;19(1). 13148-1-7.

[25] Redl A, Morel MH, Bonicel J, Vergnes B, Guilbert S. Rheological properties of gluten plasticized with glycerol: dependence on temperature, glycerol content and mixing conditions. Rheol Acta 1999;38:311-20.

[26] Kim C, Sainte-Beuve J, Guilbert S, Bonfils F. Study of chain branching in natural rubber using size-exclusion chromatography coupled with a multi-angle light scattering detector (SEC-MALS). Eur Polym J 2009;45(8):2249-59.

[27] Wyatt PJ. Light scattering and the absolute characterization of macromolecules. Anal Chim Acta 1993;272:1-40.

[28] Dorgan JR, Janzen J, Knauss DM, Hait SB, Limoges BR, Hutchinson MH. Fundamental solution and single-chain properties of polylactides. J Polym Sci B 2005;43:3100-11.

[29] Podzimek S. Light scattering, size exclusion chromatography and asymmetric flow field flow fractionation: powerful tools for the characterization of polymers, proteins and nanoparticles. New York: Wiley; 2011.

[30] Sosnowski S, Gadzinowski M, Slomkowski S. Poly(1,1-lactide) microspheres by ring-opening polymerization. Macromolecules 1996;29:4556-64.

[31] Mohd-Adnan AF, Nishida H, Shirai Y. Evaluation of kinetics parameters for poly(L-lactic acid) hydrolysis under high-pressure steam. Polym Degrad Stabil 2008;93:1053-8.

[32] Turner JF, Riga A, O'Connor A, Zhang J, Collis J. Characterization of drawn and undrawn poly-L-lactide films by differential scanning calorimetry. J Therm Anal Calorim 2004;75:257-68.

[33] Yasuniwa M, Tsubakihara S, Sugimoto Y, Nakafuku C. Thermal analysis of the double melting behavior of poly(L-lactic acid). J Polym Sci B 2004;42: 25-32.

[34] Yasuniwa M, Tsubakihara S, Iura K, Ono Y, Dan Y, Takahashi K. Crystallization behavior of poly(L-lactic acid). Polymer 2006;47:7554-63.

[35] Yasuniwa M, Iura K, Dan Y. Melting behavior of poly(L-lactic acid): effects of crystallization temperature and time. Polymer 2007;48:5398-407.

[36] Yasuniwa M, Sakamo K, Ono Y, Kawahara W. Melting behavior of poly(L-lactic acid): X-ray and DSC analyses of the melting process. Polymer 2008;49:1943-51.

[37] Hoogsteen W, Postema AR, Pennings AJ, Ten Brinke G, Zugenmaier P. Crysta structure, conformation and morphology of solution-spun poly(L-lactide) fibers. Macromolecules 1990;23:634-42.

[38] Miyata T, Masuko T. Crystallization behaviour of poly(l-lactide). Polymer 1998;39:5515-21.

[39] De Santis P, Kovacs AJ. Molecular conformation of poly(S-lactic acid). Biopolymers 1968;6:299-306.

[40] Kobayashi J, Asahi T, Ichiki M, Oikawa A, Suzuki H, Watanabe T, et al. Structural and optical properties of poly lactic acids. J Appl Phys 1995;77:2957-73.

[41] Sasaki S, Asakura T. Helix distortion and crystal structure of the $\alpha$-form of poly(L-lactide). Macromolecules 2003;36:8385-90.

[42] Brizzolara D, Cantow HJ, Diederichs K, Keller E, Domb AJ. Mechanism of the stereocomplex formation between enantiomeric poly(lactide)s. Macromolecules 1996;29:191-7. 
[43] Zhang J, Duan Y, Sato H, Tsuji H, Noda I, Yan S, et al. Crystal modifications and thermal behavior of poly(L-lactic acid) revealed by infrared spectroscopy. Macromolecules 2005;38:8012-21.

[44] Kawai T, Rahman N, Matsuba G, Nishida K, Kanaya T, Nakano M, et al. Crystallization and melting behavior of ploy(L-lactic acid). Macromolecules 2007; 40:9463-9.
[45] Pan P, Kai W, Zhu B, Dong T, Inoue Y. Polymorphous crystallization and multiple melting behavior of poly(L-lactide): molecular weight dependence. Macromolecules 2007;40:6898-905.

[46] Baratian S, Hall ES, Lin JS, Xu R, Runt J. Crystallization and solid state structure of random polylactide copolymers: poly(L-lactide-co-D-lactide)s. Macromolecules 2001;34:4857-64. 